\title{
Modeling the potential change in yield and distribution of the earth's crops under a warmed climate
}

\author{
Rik Leemans ${ }^{1}$, Allen M. Solomon ${ }^{2}$ \\ 'Global Change Department, National Institute of Public Health and Environmental Protection (RIVM), \\ NL-3720 BA Bilthoven, The Netherlands
}

${ }^{2}$ Environmental Research Laboratory, U.S. Environmental Protection Agency, 200 SW 35th St., Corvallis, Oregon 97333, USA

\begin{abstract}
The large-scale distribution of crops is largely determined by climate. We present the results of a climate-crop prediction model based on the U.N. Food and Agriculture Organization cropsuitability approach, implemented in a GIS (geographic information system) environment using severa] global environmental databases. The model utilizes daily temperature and soil moisture conditions to determine the properties of the growing period. Crops are characterized by their variety-specific minimum growing period requirements and photosynthesis and respiration properties. Temperature and radiation during the growing period control the development of each crop. The model simulates cropspecific geographic distributions by demarcating the region where rain-fed productivity is possible. The model takes only non-irrigated crop productivity into account and the potential increase in productivity by technical means is not considered. The model therefore shows no potential yield in arid, irrigation-dependent regions. The simulated distributions of crops under current climatic conditions coincide largely with the current agricultural regions. Simulations with an atmospheric general circulation model (AGCM)-derived climate-change scenario illustrate changes in the agricultural potential. There are large regional differences in the response. Only high-latitude regions uniformly benefit from the climatic change with projected longer growing periods and an increased productivity. Most other regions, however, do not benefit significantly or even lose productivity after such change. In most of the latter regions differences in moisture availability control the change. The analysis shows that agricultural potential and impacts of climatic changes can be simulated comprehensively.
\end{abstract}

\section{INTRODUCTION}

The concentrations of greenhouse gases (GHGs) are increasing rapidly (Houghton et al. 1992). This increase could lead to large changes in regional and seasonal climate patterns during the coming century (Gates et al. 1992). Changing climate could strongly influence the current distribution and productivity of crops. For this paper, we define 'crops' as agronomic varieties of food crops. Blasing \& Solomon (1984) defined several climatic 'rules' from the current distribution of the American corn belt and applied these rules to map corn belt distribution under a changed climate. They illustrated the migration and shrinkage of this belt as a result of such climatic change. Similar conclusions were drawn for the American wheat regions by Rosenzweig (1985). Parry et al. (1988) introduced the concept of analogue agriculture regions to define the agricultural potential of several regions after climate change. They not only emphasized the distributional constraints by climate on specific crops, but also accounted for farming systems and their economy. Rosenberg \& Crosson (1991) used a suite of ecological, agricultural, and economic models to assess socio-economic impacts of climatic change for the central United States. They clearly showed which economic sectors could benefit and which could decline under warming conditions. Parry (1992) examined a comprehensive suite of future agricultural impacts. 
Although they discuss the potential magnitude of change, most of the agricultural studies reviewed above focus on a single region or several regions and do not provide a comprehensive global assessment. Large regions of the third world, including Africa and South America, are rarely considered.

The primary aim here is to predict global crop distributions and productivity. In addition, the model applied here was designed to link with a temporally and spatially explicit set of models which determine land use, GHG emissions, and climate change by using estimates of global agricultural and natural vegetation potentials, atmospheric $\mathrm{CO}_{2}$ concentrations, and their feedbacks with other components of the earth's system (Alcamo et al. in press). The model should therefore be simple enough to run efficiently on current computers, but must still mimic the most important processes of crop growth and development in order to simulate a realistic response to climatic change. For this purpose, rudimentary crop-distribution models often based on only a few temperature indices (cf. Parry 1992, Rosenzweig 1993) would be unsuitable because they neglect seasonal climatic variables which will actually limit future crop distributions under changing climate. The globally comprehensive rule-based model of Cramer \& Solomon (1993, this volume), which uses several relevant climatic parameters, does not predict crop productivity. On the other hand, phenologically accurate and detailed crop models, like SPAW (SoilPlant-Air-Water) (Saxton et al. 1992), cannot be globally comprehensive because of their great computational and data requirements.

Rind et al. (1992) point out that water balance is of utmost importance in a global climate impact model. In most regions of the world, temperature is adequate for growth and moisture is a primary limiting factor, either alone or as a stress induced by evaporation demand resulting from high temperature. The model should therefore include a realistic simulation of water balance and soil moisture.

The paper focuses on climate-controlled distribution of major crops and crop productivity. The crop-suitability approach of the United Nations Food and Agricultural Organization (FAO) is employed with simplifications to allow its global application to simulate current and future distributions of several major crops (Anonymous 1978). The current analysis was limited to single cropping systems. Irrigated agriculture or techniques to improve production, such as variations in use of fertilizer supplements and mechanical equipment, were not considered. Although the model may exclude crops from places where they do not now grow, the model is assumed to be inaccurate if it implies crops cannot be grown in areas where they do indeed thrive.

\section{METHODS}

Climatic constraints. Like natural vegetation patterns (Prentice 1992, Cramer \& Leemans 1993), the global distribution of crops is largely determined by climate. The boreal regions exclude crops because of the extremely low temperatures (Cramer \& Solomon 1993, this volume, p. 97-110). The temperate regions combine mild winters, adequate growing season warmth and moisture with technological capability to reach the maximum potential crop production. Many cereal crops, such as maize (Zea), wheat (Triticum), and barley (Hordeum), produce high yields (yield is the amount of desired plant product per growing season per unit area). Tropical latitudes lack killing frosts and possess temperatures warm enough to support growth during the entire year. Low-temperature intolerance and high productivity adapt many crops, such as maize, millet (Eleusine, Panicum, Setaria, Echinochloa, Pennisetum, etc.) cassava (Manihot) and sugar cane (Saccharum), to the tropical climate. Because there is always adequate warmth to grow, crop distributions within tropical and subtropical regions are determined by the available water. This includes the entire water balance depending on precipitation, evapotranspiration and soil moisture, the latter being the primary moisture variable to which plants respond.

The projections of future crop distributions and yields used here are derived from the agro-ecological zones and crop suitability projects of the FAO (Anonymous 1978, Higgins et al. 1987). The FAO approach was mainly developed for tropical and subtropical regions, but the methodology was modified for cooler regions as well. The central concept of the approach is that of the growing period, i.e. that period during the year when warmth and soil moisture are adequate for growth. We implemented this definition using the Priestley-Taylor water balance model (Cramer \& Prentice 1988, Prentice et al. 1993) and a climatic database for temperature and precipitation with $0.5^{\circ}$ longitude and latitude resolution (Leemans \& Cramer 1991). This water balance model was developed especially for use at the landscape scale and it adequately captures regional differences in soil water content and actual evapotranspiration (Cramer \& Prentice 1988). Potential evapotranspiration (PET) is driven by the radiation balance at specific locations. The actual evapotranspiration (AET) is a function of precipitation and available soil moisture. It is limited by the maximum supply rate of soil moisture and by the soil moisture capacity, determined from a data base on soil properties (Prentice et al. 1992). This water balance approach differs from the original FAO methodology, which combined the PET formulation of Penman (1948) with a simple soil water balance model. The 
FAO PET formulation is data-demanding and adequate data with a global coverage are unavailable. The empiricism of other available water balance approaches, such as those based on the widely used Thornthwaite PET scheme (Thornthwaite \& Mather 1957), is inappropriate for extrapolation in to the future.

The growing period for crops is characterized by the annual pattern of daily temperature, precipitation, and soil moisture (Fig. 1). By definition, growth occurs only above $5^{\circ} \mathrm{C}$. The definition of the moisture seasons is more complex and follows the rationale given in Anonymous (1978). In regions with a distinct dry season (inadequate moisture availability), the growing period starts arbitrarily when precipitation $(P)$ equals half the PET. The rationale is that the first precipitation to fall on the surface of a soil with a large moisture deficit can be utilized immediately for seed germination and early growth. The soil moisture therefore need not be replenished completely (Anonymous 1978). A successful crop life cycle, however, requires a period when the evapotranspiration demands of a plant under a full canopy cover can be met. Thus, the growing season should include a period of precipitation surplus $(P>$ PET) which coincidentally replenishes the soil moisture deficit. Finally, at the end of the humid period $(P>$ PET), crop growth and development depend on the available soil moisture. This is often the period when the crops mature.

The annual temperature regime is given by the lower bar at the bottom of each graph in Fig. 1, while the annual moisture regime is represented by the upper bar and the body of the diagrams. The characteristics of different growing periods as computed by the present scheme did not differ significantly from those given in Anonymous (1978). A global map with the length of the growing period (Fig. 2) distinguishes the regions where temperature is the limiting factor (high latitudes) and those where moisture availability is limiting (arid lands in the mid and low latitudes). The regions with a year-round growing period are located in the wet
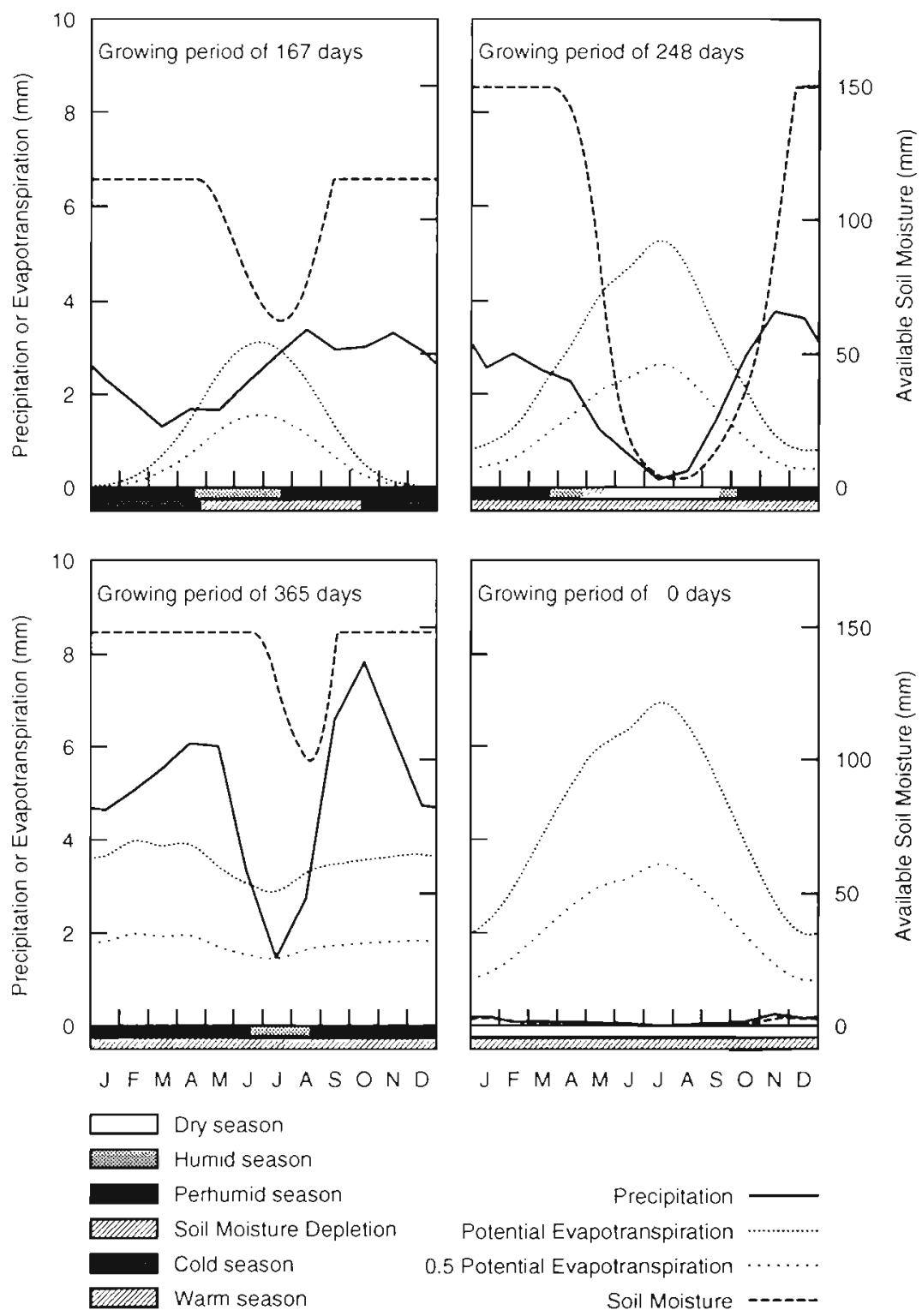

Fig. 1. Annual curves that determine the characteristics of the growing period. Upper left: a typical temperate climate with a distinct winter period and no pronounced dry period. Upper right: a sub-tropical climate without a cold period, but with a distinct dry period during summer. Lower left: a tropical climate with a distinct seasonality in rainfall, resulting in a short dry period. Lower right: a hot desert climate with little precipitation and no growing period. Annual temperature regime indicated by lower bar at the bottom of each graph, annual moisture regime by upper bar. The definitions follow those given in Anonymous (1978) tropics around the equator, the southeast United States, and southeast Asia.

A successful crop harvest requires success in all life cycle stages: germination, growth, flowering, and seed maturation. The phenology of these stages is influenced by different climatic constraints. The model defines a minimum period to grow each crop to mimic its time-dependent phenology (see Table 1). In some crops a cold or dry season is required to obtain har- 
Length of growing season (\# days) for year 1970

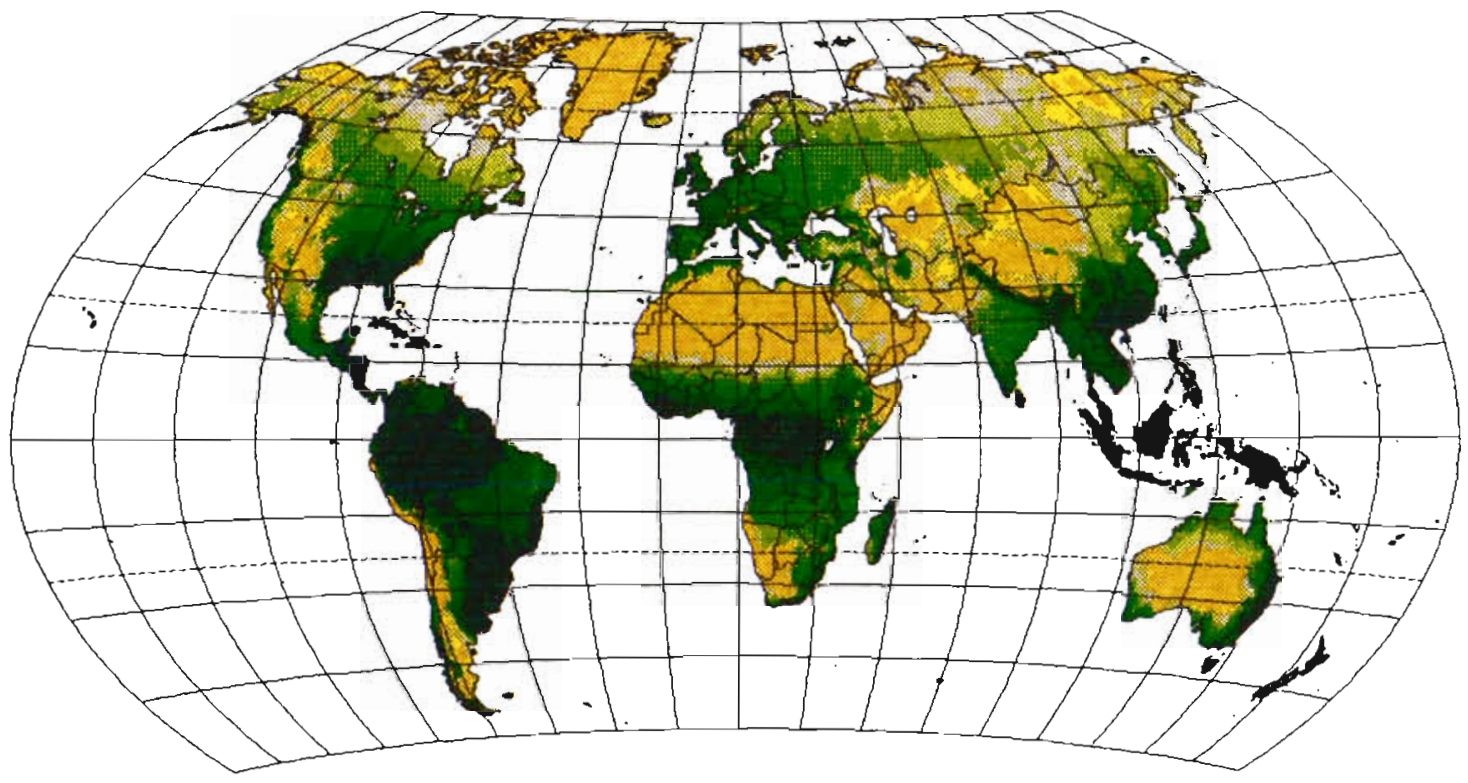

Length of growing season (\# days) for year 2050

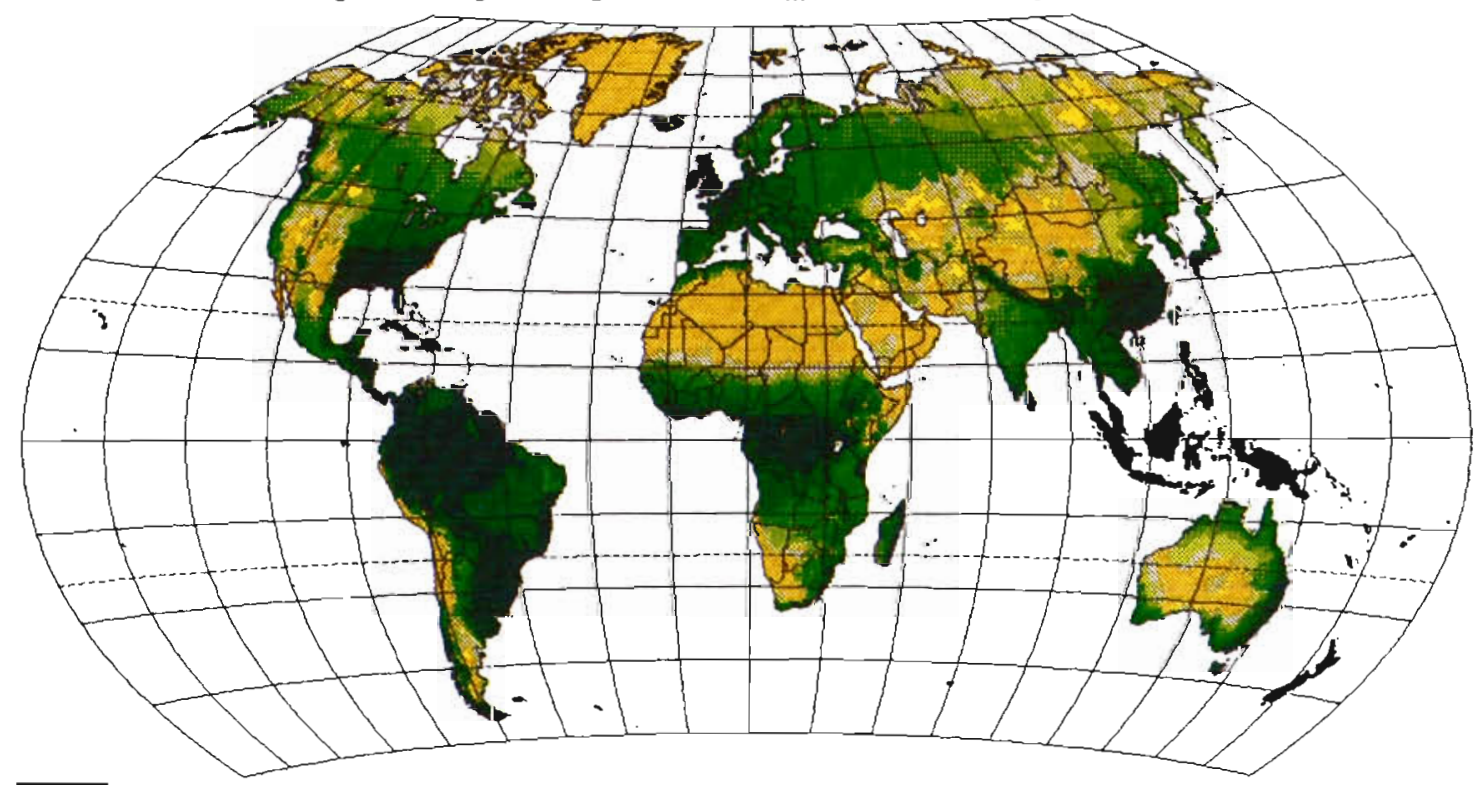

$>364$

$$
\begin{aligned}
& 330-364 \\
& 300-330 \\
& 240-300 \\
& 210-240 \\
& 180-210 \\
& 150-180
\end{aligned}
$$$$
\begin{array}{r}
120-150 \square \\
90-120 \square \\
60-90 \square \\
30-60 \\
1-30 \square \\
\leq 1
\end{array}
$$

Fig. 2. World map showing the length of the growing period defined by the modified agro-ecological zone system, in days, for current and future climatic conditions 
Table 1 Climatic crop requirements for 10 major crops. GPL: length of growing period; MTR: temperature of coldest month; AAT: active accumulated temperature; MR: $\alpha$-moisture index; CT: crop type; Hi: Harvest index

\begin{tabular}{|c|c|c|c|c|c|c|}
\hline & $\begin{array}{l}\text { GPL } \\
\text { (d) }\end{array}$ & $\begin{array}{c}\text { MTR } \\
\left({ }^{\circ} \mathrm{C}\right)\end{array}$ & $\begin{array}{l}\text { AAT } \\
\left({ }^{\circ} \mathrm{C}\right)\end{array}$ & MR & CT & $\mathrm{Hi}$ \\
\hline Temperate maize & $\geq 130$ & -20.0 to 15.0 & $\geq 1500$ & None & III & 0.3 \\
\hline Tropical maize & $\geq 175$ & $\geq 5.0$ & $\geq 3000$ & None & IV & 0.3 \\
\hline Spring wheat & $\geq 80$ & $<5.0$ & $\geq 1000$ & None & I & 0.4 \\
\hline Winter wheat & $\geq 170$ & $<10.0$ & $\geq 1250$ & None & I & 0.3 \\
\hline Rice & $\geq 135$ & $\geq-7.5$ & $\geq 2250$ & $\geq 0.95$ & II & 0.3 \\
\hline Millet & $\geq 80$ & $\geq-25.0$ & $\geq 1500$ & $<0.95$ & IV & 0.2 \\
\hline Soybeans & $\geq 125$ & $<20.0$ & $\geq 2000$ & None & II & 0.4 \\
\hline Beans & $\geq 110$ & $<20.0$ & $\geq 1000$ & None & I & 0.4 \\
\hline Sugar cane & $\geq 240$ & $\geq 10.0$ & $\geq 4500$ & $\geq 0.95$ & III & 1.0 \\
\hline Cassava & $\geq 180$ & $\geq 10.0$ & $\geq 4500$ & None & II & 0.7 \\
\hline
\end{tabular}

vestable yields. For winter varieties like winter wheat, the model assumes that germination takes place at the end of the previous growing period and development is completed in the current growing period. The required length of the growing period is adjusted accordingly. However, a complete set of crop requirements is more complex than the model can handle and the length of the growing period alone does not define all constraints. For example, specific temperatures could determine whether a particular developmental stage begins or not, when it will begin, and at what rate it will develop.

These additional climatic requirements were implemented in the original FAO climatic crop suitability system by defining climatic regions (Higgins et al. 1987), each characterized by specific temperature and moisture limits (e.g. moderately cool tropics and warm subtropics with summer rainfall). Each crop variety was subsequently assigned to one or more suitable zones. Unfortunately, the zone definitions were inappropriate for a global model. Only the tropical and subtropical regions were distinguished by the climate classification; the temperate and boreal zones were undifferentiated despite their very different crop suitabilities. Also, classes overlapped in some warm regions where the growing period was long enough to also include another, cooler zone, mimicking multiple cropping systems.

To overcome these problems we adopted an approach similar to that of Solomon (1986). Because weather records provide mean temperatures and chilling requirements are a function of minimum rather than mean temperatures, chilling requirements are simulated for winter wheat and temperate maize using regressions between the mean temperature of the coldest month and the absolute minimum temperature. Warmth requirements during the growing period are then defined using the accumulated temperature above $5^{\circ} \mathrm{C}$ (active accumulated temperature). Drought requirements during the maturation periods are simulated by maximum values of the Priestley-Taylor $\alpha$-moisture index (AET:PET; cf. Cramer \& Prentice 1988). The ranges of the climatic variables for the several common crop varieties we simulated are given in Table 1. The values defined are only those that could be justified on the basis of crop-specific phenology and requirements provided by Table 1 of Anonymous 1978.

Crop productivity. If a crop could be grown based on the climatic constraints in Table 1, the model of de Wit (1965) determined its productivity. The model was implemented using the FAO crop-suitability approach to calculate the net biomass production and yield of crops from their climate and photosynthetic properties. Only the general framework and modifications of the original approach (Anonymous 1978) are discussed here. It is assumed that a constant average growth rate occurs during the growing period. Total yield of a crop is determined by both photosynthesis and respiration processes, given by:

$$
B_{Y}=H_{1}\left(B_{\mathrm{g}}-R\right)
$$

where $B_{\mathrm{Y}}=$ total yield; $B_{\mathrm{g}}=$ gross biomass production; $R=$ respiration loss; and $H_{1}=$ the harvest index, an index that converts total biomass production into the fraction of each crop representing economically useful yield.

Photosynthesis is limited by the amount of photosynthetically active radiation (PAR), which depends on location and cloudiness. Orientation and slope can be taken into account explicitly (Swift 1976). The tables of de Wit (1965) were used to transform PAR values between clear sky and overcast conditions to their respective photosynthetic rates ( $B_{c}$ and $B_{o} ;$ Fig. 3). Those values reached $20 \mathrm{~kg} \mathrm{ha}^{-1} \mathrm{~h}^{-1}$ for crops with closed canopy and were decremented by average cloudiness. We computed the average cloudiness during the growing period from the IIASA climate database (Leemans 

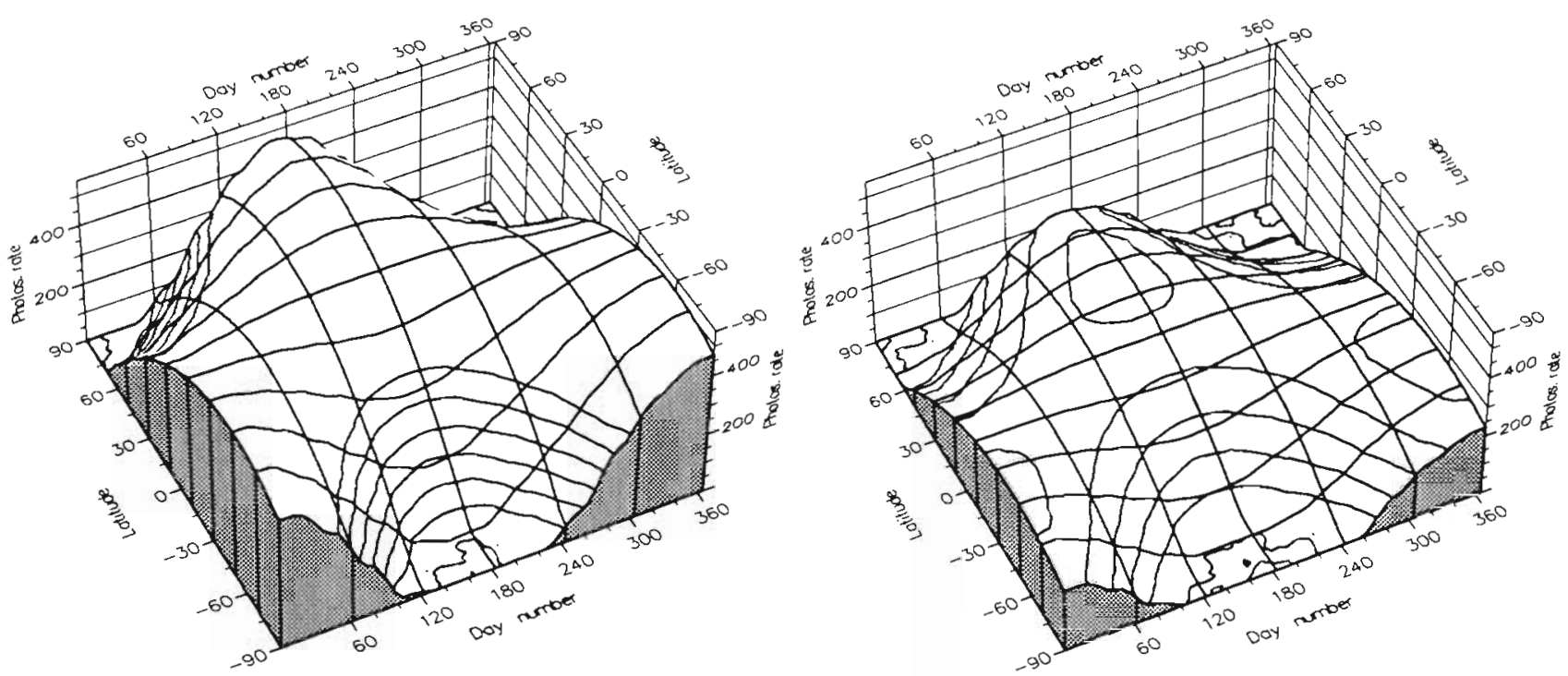

Fig. 3. Average rate of gross biomass production ('Photos. rate', in $\mathrm{kg} \mathrm{ha}^{-1} \mathrm{~h}^{-1}$ ) at $20^{\circ} \mathrm{C}$ throughout the year under a clear sky (left) and with a complete cloud cover (right) (after de Wit 1965)

\& Cramer 1991) to get a local overcast fraction $(F)$. The local average photosynthetic rate throughout the growing period $\left(B_{\mathrm{gp}}\right)$ is then defined as:

$$
B_{\mathrm{gp}}=F B_{\mathrm{o}}+(1-F) B_{\mathrm{c}}
$$

where $B_{\mathrm{o}}=$ overcast production and $B_{\mathrm{c}}=$ clear-sky productivity rate.

Maximum gross biomass production further is strongly temperature dependent. This temperature dependence is crop-specific. All crops are classified into 4 crop types with respect to temperature response of photosynthesis and photosynthetic pathway (Anonymous 1978) (Table 1). Crop types I and II incorporate the $\mathrm{C}_{3}$ photosynthetic pathway and types III and IV the $\mathrm{C}_{4}$ pathway (Bazzaz \& Fajer 1992). A minimum, optimal, and maximum temperature can be established for each crop type (see Fig. 4).

Photosynthesis occurs only during daylight and the input temperature therefore is the daytime temperature during the growing period. This temperature is rarely given in climate databases, so the mean maximum temperatures were used instead. The mean temperatures in climatic records may not be appropriate for this purpose because they are often the average between mean maximum (i.e. day) and minimum (i.e. night) temperatures.

Gross biomass production $\left(B_{\mathrm{g}}\right)$ was determined from the average growing period temperature and $B_{\mathrm{g} p}$ (Anonymous 1978). The respiration is a linear function of both the gross biomass and the total accumulated biomass. The first is a constant, temperature-independent function, but the latter, maintenance respiration, increases exponentially with growing-period temperatures. The temperature response of the maintenance respiration coefficient $\left(C_{t}\right)$ is given in Fig. 4. This response is similar for most crops and differs only for legumes. Maintenance respiration occurs, in contrast to photosynthesis, both during day and night. We therefore used mean temperature during the growing period to define the respiration response.

Net biomass production (Eq. 1) for a specific growing period length $(N$, in days) is:

$$
B_{\mathrm{n}}=0.36 B_{\mathrm{g}} /\left(1 / N+0.25 C_{\mathrm{t}}\right)
$$

This net biomass production is for a crop with a closed canopy. The production at lower cover was not adjusted, on the assumption that the smaller productivity before canopy closure balanced the larger productivity after closure. However, during the maturation phase of many cereals, only biomass accumulation occurs. Here the model may overestimate net biomass production. This can be especially important in those areas where the climatic conditions are marginally suitable and the period to grow to closedcanopy conditions occupies the major part of the growing period.

Climate change scenarios. Most atmospheric general cirulation models (AGCMs) produce a similar pattern of warming with increased GHG concentrations but large differences still remain in the magnitude of change. Generally, high latitude regions should experience a larger temperature increase than do low latitude regions, and the temperature increase should be greater in the winter season than in the summer season 
Fig. 4. Photosynthetic and respirational characteristics of crop types (see Table 1) (after Anonymous 1978)
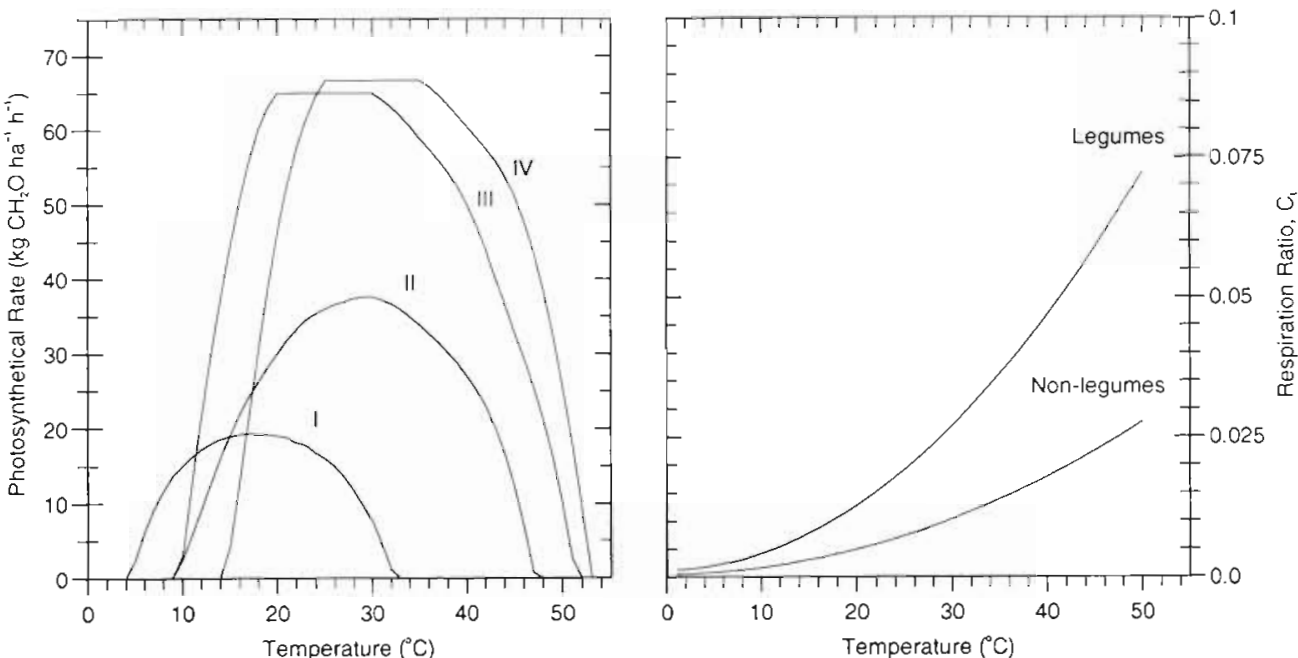

(cf. Mitchell et al. 1990). Precipitation produces a much less repeatable pattern, but all AGCMs agree that precipitation should increase globally with increased intensity of the hydrological cycle. The use of AGCMs as estimates of future climate provides geographically realistic scenarios (Carter et al. 1992), and the potential range of changes can be gleaned by the use of scenarios from several AGCMs (Smith et al. 1992).

We used a single AGCM scenario [based on a single and doubled $\mathrm{CO}_{2}$ run by Manabe \& Wetherald 1987 , referred to as the GFDL (Geophysical Fluid Dynamics Laboratory) scenario] to simulate the crop response to climatic change. We overlaid the AGCM-simulated climatic change on the IIASA gridded climate database (Leemans \& Cramer 1991) to obtain high spatial resolution with realistic topography while retaining the geographic trend of the simulated climatic change. Seasonal changes were dervied by applying the climatic changes to all monthly values. Future temperature values $\left(T_{f}\right)$ were obtained from the measured temperatures values $\left(T_{C}\right)$ by the addition of the temperature changes in the AGCMs $\left(T_{\mathrm{f}(\mathrm{GCM}\}}-T_{\mathrm{C}(\mathrm{GCM})}\right)$ :

$$
T_{\mathrm{f}}=T_{\mathrm{C}}+\left(T_{\mathrm{f(GCM})}-T_{\mathrm{C}(\mathrm{GCM})}\right)
$$

To avoid negative precipitation values in climate scenario values $\left(P_{\mathrm{f}}\right)$, we multiplied current monthly precipitation values $\left(P_{c}\right)$ by precipitation differences:

$$
P_{\mathrm{f}}=P_{\mathrm{c}}\left(P_{\mathrm{f}(\mathrm{GCM})} / P_{\mathrm{C}(\mathrm{GCM})}\right)
$$

Here we assume climate resulting from doubled $\mathrm{CO}_{2}$ occurs by the year 2050 (Bretherton et al. 1990) based on a 'business-as-usual' scenario (Scenario IS92e: Houghton et al. 1992).

Verification of the model. We implemented the water balance model, growing period calculations and the production calculation in a dedicated geographic information system (GIS) system that combines databases, models and several statistical tools with climate change scenarios (Leemans 1992). In addition to the monthly data in the climate data base (Leemans \& Cramer 1991), we needed daily climatic input values. These were obtained by using a quadratic spline interpolation from monthly values.

The crop distribution model was implemented for 10 different crops (Table 1) and based on parameter values given by Anonymous (1978). These crops were selected for their wide coverage of different regions of the world (both climatologically and economically) and for their worldwide abundance and importance. Table 2 lists the maximum yield and current extent of these crops

With one exception, the simulated average yield is between 1.2 and 2 times higher than the observed average yield. A similar pattern is obtained for the

Table 2. Average and maximum observed and simulated yield (t ha $\mathrm{h}^{-1}$ ) for various crops on the current landscape. The observed values are obtained from the FAO databases on crop statistics

\begin{tabular}{|lrrrr|} 
& \multicolumn{2}{c}{ Observed yield } & \multicolumn{2}{c|}{ Simulated yield } \\
& Avg. & Max. & Avg. & Max. \\
\hline Temperate maize & 4.8 & 7.3 & 7.7 & 9.6 \\
Tropical maize & 5.8 & 8.4 & 9.6 & 11.0 \\
Spring wheat & 2.8 & 3.5 & 3.8 & 4.6 \\
Winter wheat & 4.1 & 5.4 & 6.5 & 7.1 \\
Rice & 3.5 & 4.3 & 4.8 & 5.4 \\
Millet & 0.9 & 2.2 & 2.1 & 3.8 \\
Soybeans & 1.9 & 3.5 & 3.9 & 5.7 \\
Beans & 1.4 & 2.4 & 3.2 & 2.8 \\
Sugar cane & 64.0 & 81.0 & 55.0 & 65.4 \\
Cassava & 10.2 & 23.8 & 18.7 & 28.4 \\
\end{tabular}


maximum yields although the differences are smaller (1.2 to 1.7 times). The model thus simulates systematically higher productivity than that obtained in reality. The potential area and yield which we simulate is rarely reached by actual production and crop distributions. Also, the model does not account for growth reductions because of soil limitation and non-optimal management and technologies.

Sugar cane produces the only simulated yield lower than measured (ca-15\%). The model assumes that sugar cane needs a growing period of at least $240 \mathrm{~d}$. The maximum simulated length of the growing period, however, is a year (365 d), while sugar cane often grows for $1.5 \mathrm{yr}$ before being harvested. When this biennial growing period is taken into account, the potential productivity of sugar cane per growing season is similar to the yield of the other crops.

The actual distribution of these crops is illustrated on maps in e.g. Goode's Atlas (Espenshade \& Morrison 1991). These maps are based on FAO census data. We used these maps to visually assess the accuracy of the simulated potential distributions of the major crops (see Fig. 5). The simulated patterns are reasonable matches for those on the maps. The obvious systematic difference is that potential crop distribution covers more area than the actual distribution.

Two reasons for this difference seem obvious. First, a region can be climatologically suitable, but other constraints (lack of farming activity, lack of appropriate topography or substrate, lack of mechanization, etc.) can limit aqriculture. This may be particularly true in the continental wet tropics where warmth and moisture are abundant but soil fertility often is limiting. Second, many important agricultural regions are located in river valleys, river deltas and along the coast lines, where the highest human population densities occur. These regions generally have good water supplies (at least for irrigation) and fertile soils. Cultivation has been introduced into more remote regions only during the last few decades, with increasing population densities and improved inland infrastructure. The cultural and land-use history is therefore also of major importance in determining the current distribution of crops.

Although the visual comparison of the simulated crop distribution with real-world maps provides some indication of model performance, an objective measure is also required (Monserud \& Leemans 1992). Here we used digitized databases on cultivation intensity (Matthews 1983, 1985) and agricultural land cover (Olson et al. 1985). For comparison, we also created a global map for regions with an agricultural potential by combining all potential crop maps. Comparing documented and simulated geographic distributions, we obtained a Kappa statistic of 0.79 , defined as very good agreement (Monserud \& Leemans 1992). In addition, $95 \%$ of the current agriculture area was located within the potential area. Most of current agriculture which occurred outside the simulated agriculture area was in regions where water is supplied by rivers and irrigation, especially in the arid regions, like the Nile River and its delta. Agriculture in those regions is strongly dependent on irrigation.

\section{RESULTS}

\section{Changes in growing period}

Under a GHG warming, a general increase of more than $20 \%$ in the growing period occurs in the high latitude regions all around the world (Fig. 5). In many places, the growing period begins more than a month early. The growing season increase is caused mostly by increasing temperatures.

The warmer temperature in mid latitudes has significant impacts on the water balance. An enhanced dry period occurs during the summer season in arid northern Mexico, the southwestern United States, southeast Asia, and southern France. In contrast, the central deserts of Australia show a large increase in growing season. This is due to increased precipitation coupled with a slight increase in temperature.

The growing season shifts only slightly in tropical regions. Most changes are moisture related. Despite increased evaporative demand, increased precipitation enhances the growing season in the western Sahelian region. Here agricultural production could increase, although conditions remain marginal. These moisture related changes should be treated cautiously, because AGCMs are notoriously inaccurate in simulating changes in precipitation. However, that changes in crop growing period properties are determined by future temperatures at high latitudes and by future precipitation at low latitudes is indeed a reliable implication of this simulation.

\section{Future crop distribution and productivity}

Maize (Zea). We used the FAO definitions for 2 different types of maize: a tropical and a temperate variety (Table 1). The distribution of tropical maize changes little (Fig. 5c, d), while the poleward shift of temperate maize is large (cf. Fig. 5a, b). The combined area where maize can be grown increases by almost $17 \%$, and that of temperate maize alone by almost $30 \%$ (Table 3). Additionally, yield generally increases greatly for temperate maize $(27.7 \%$ worldwide; Table 4) and slightly less (12.7\%) for tropical maize. 

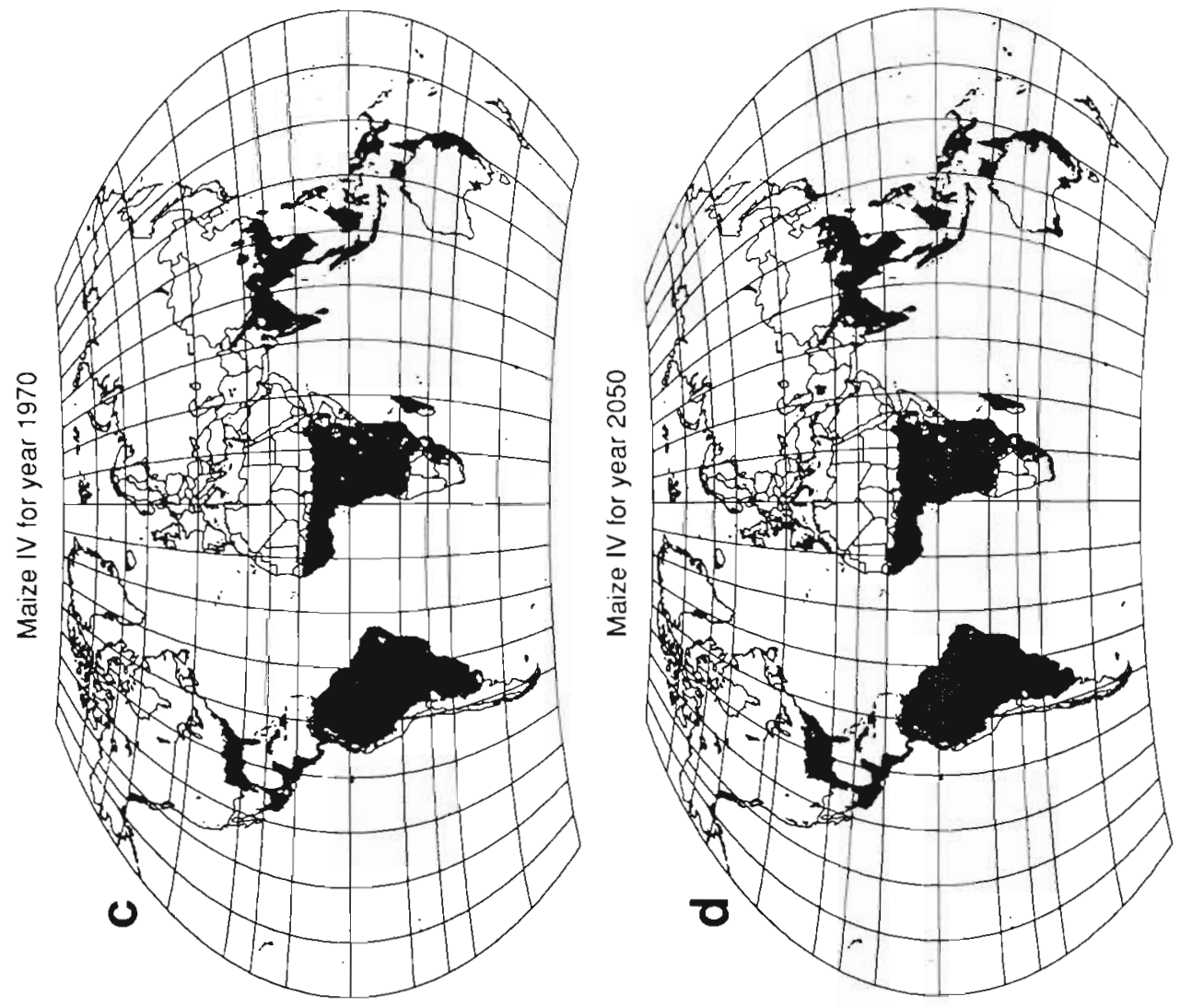

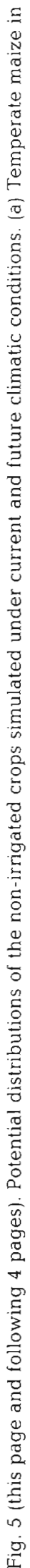
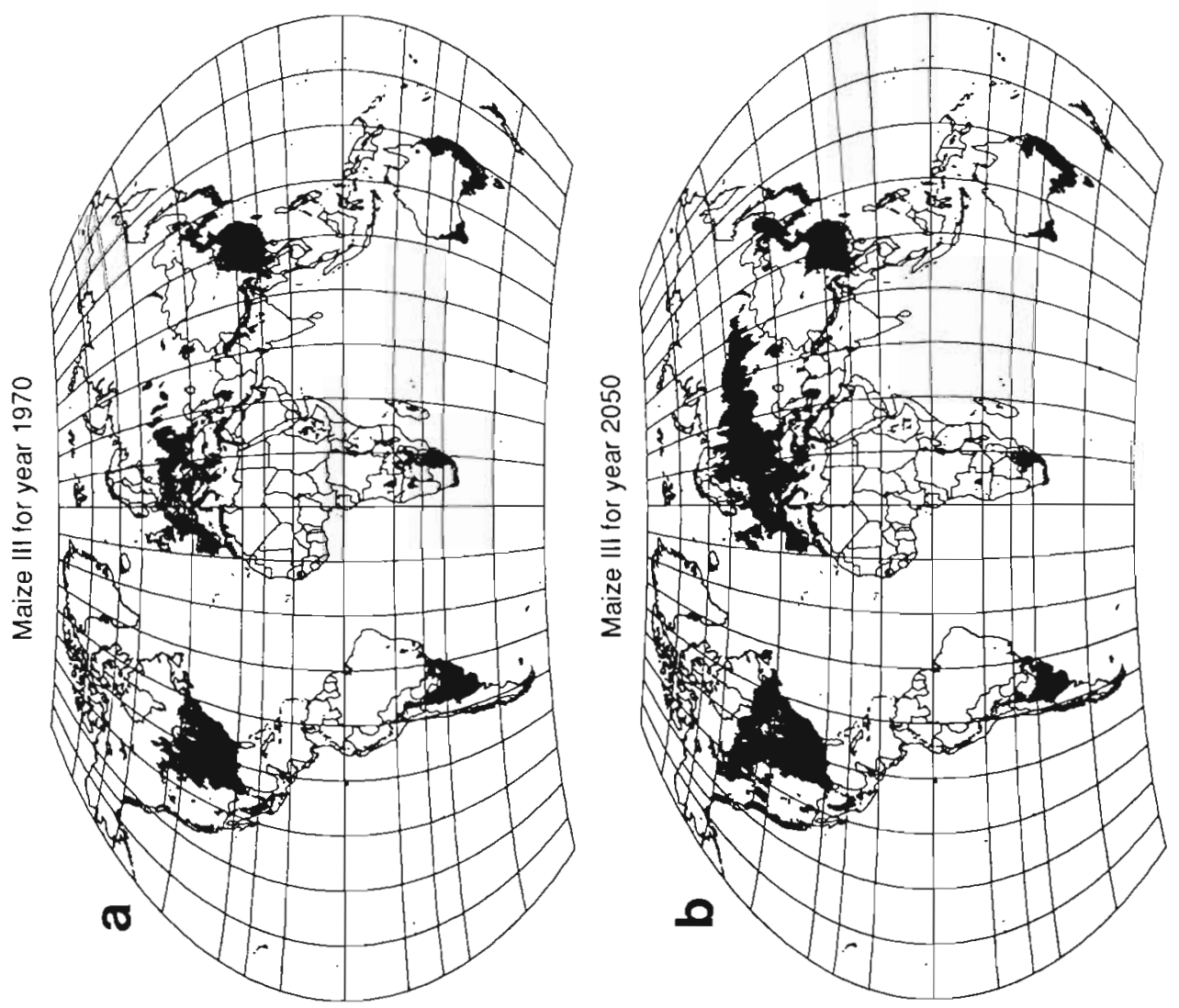

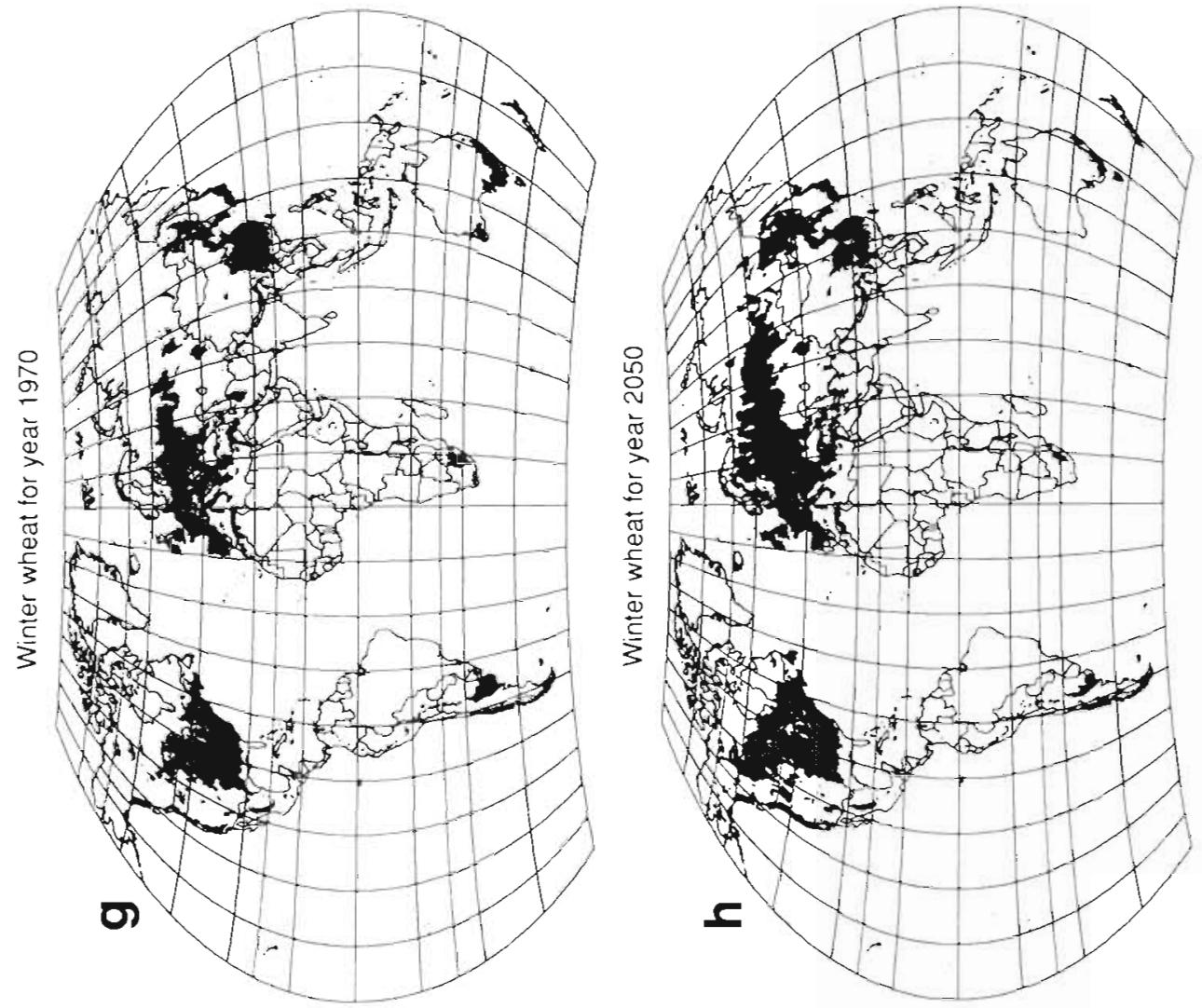

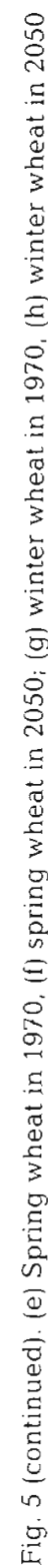
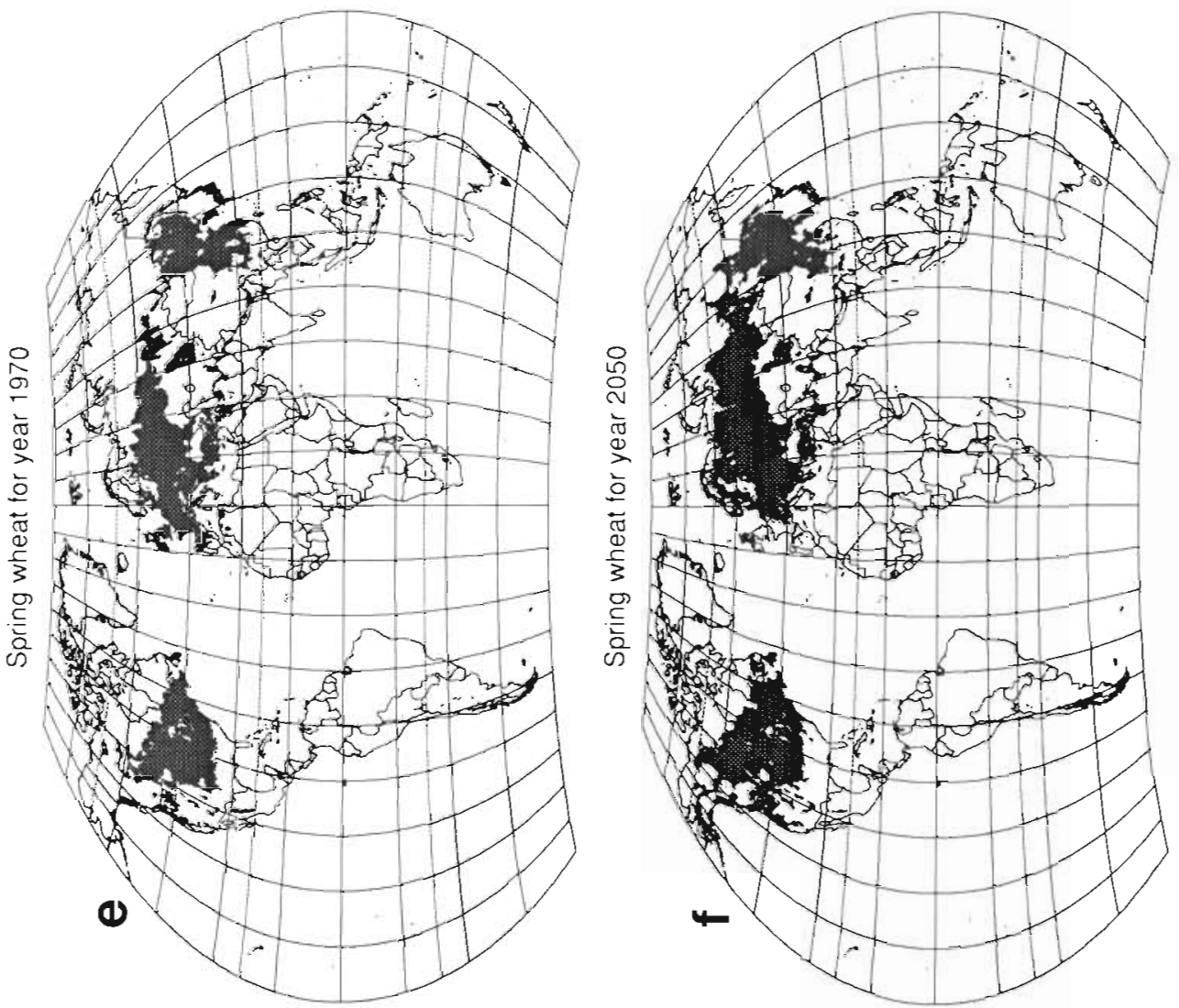

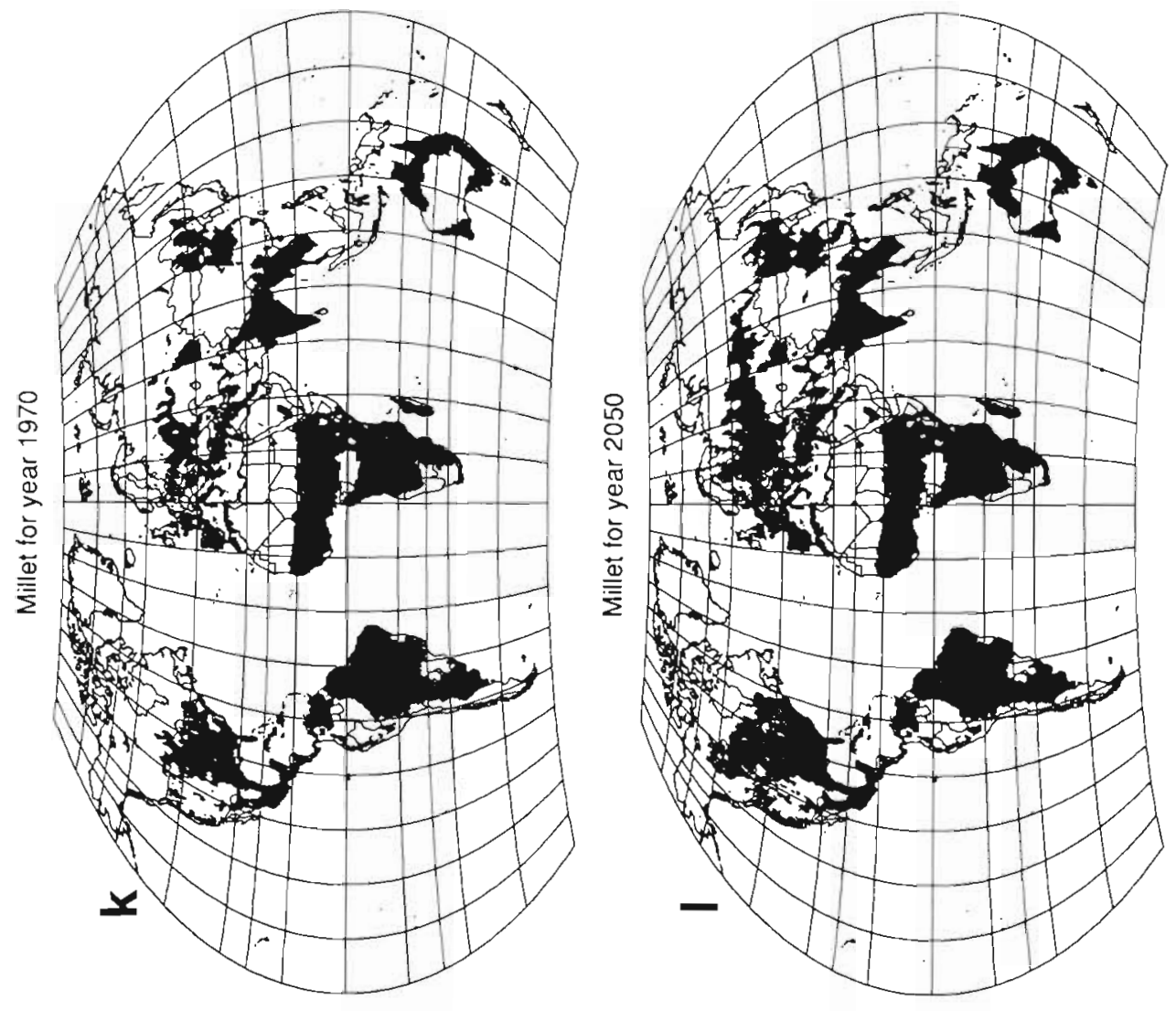

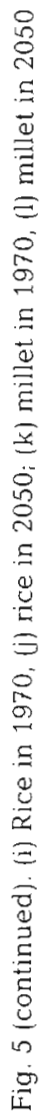
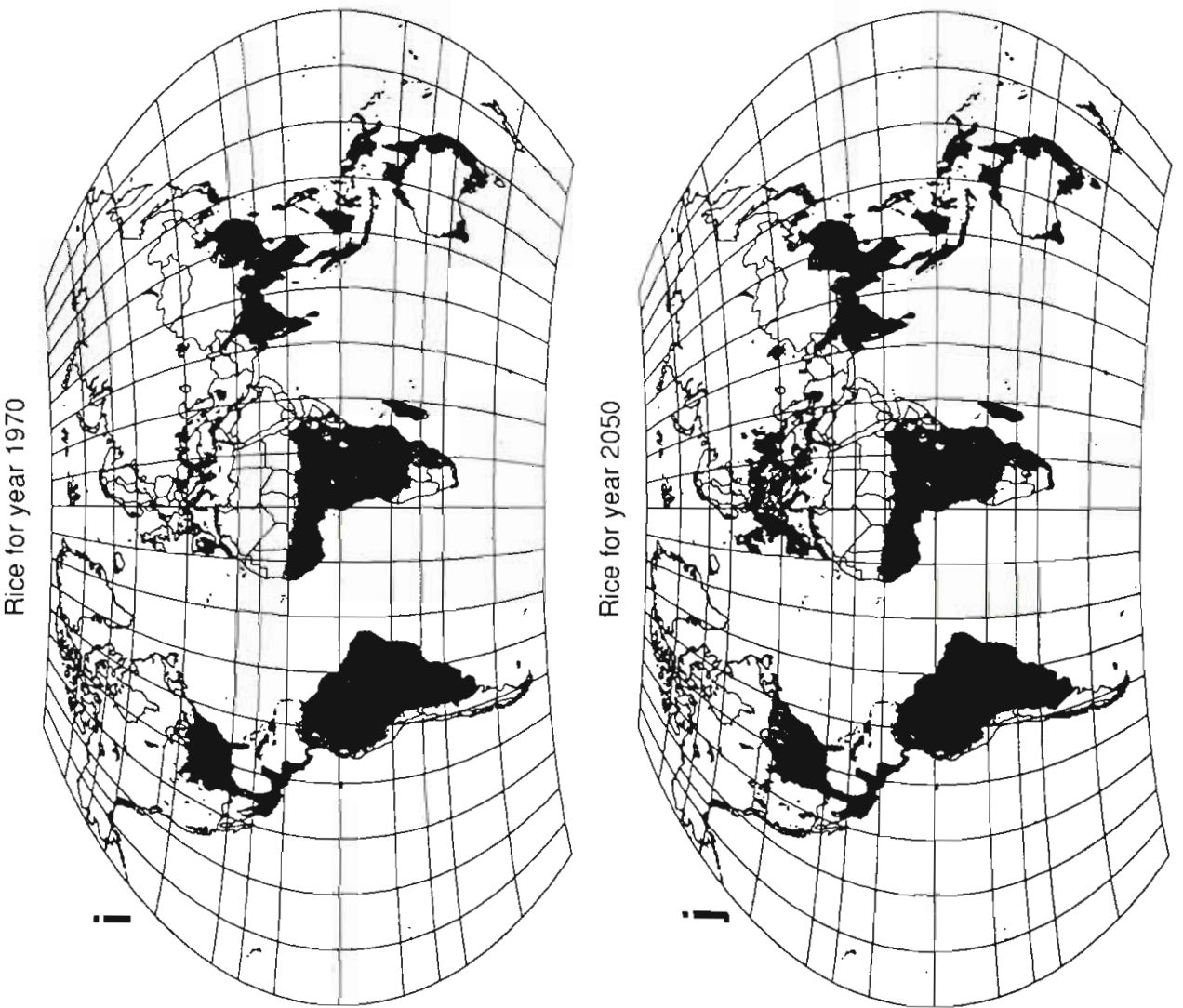

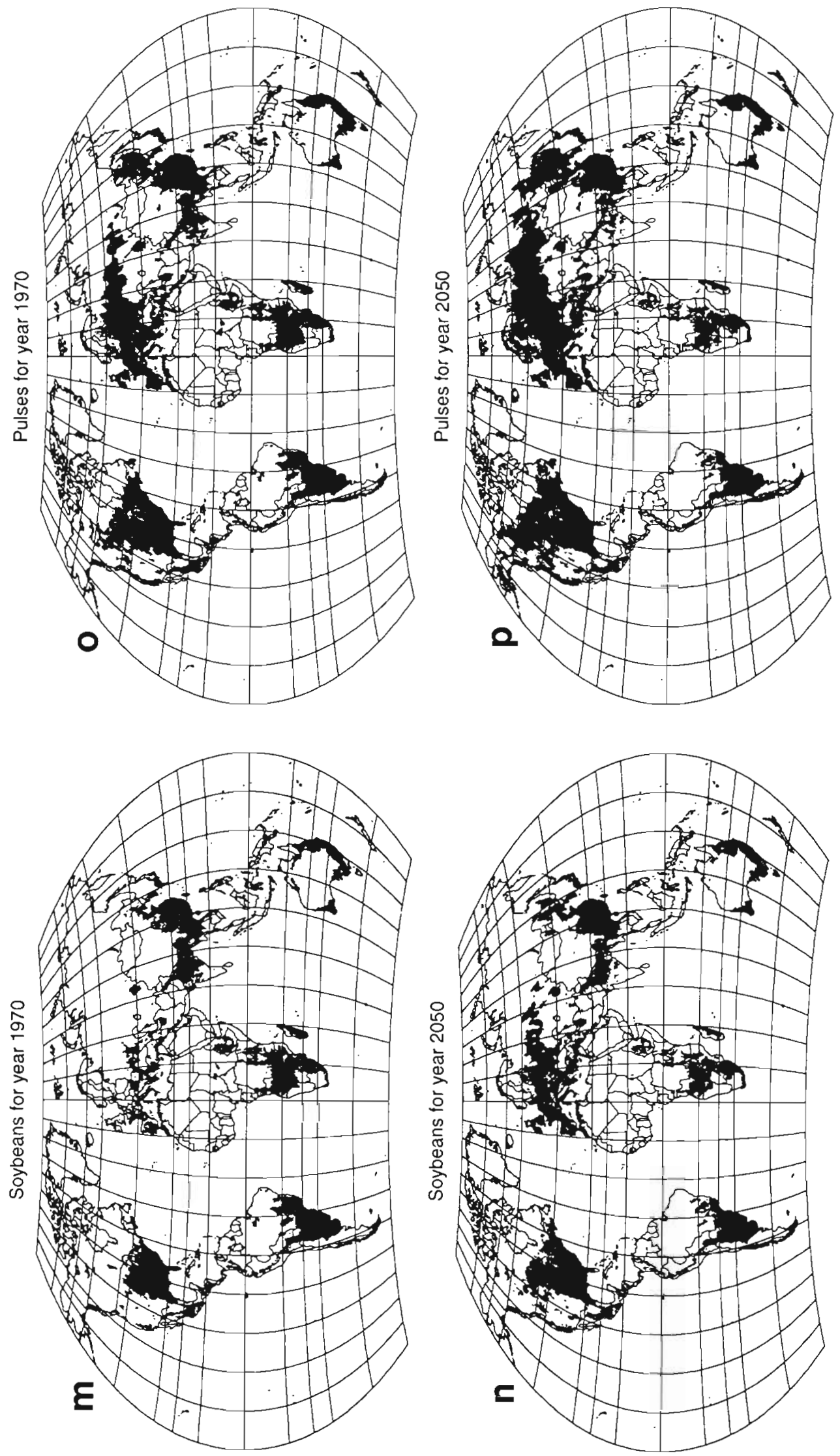

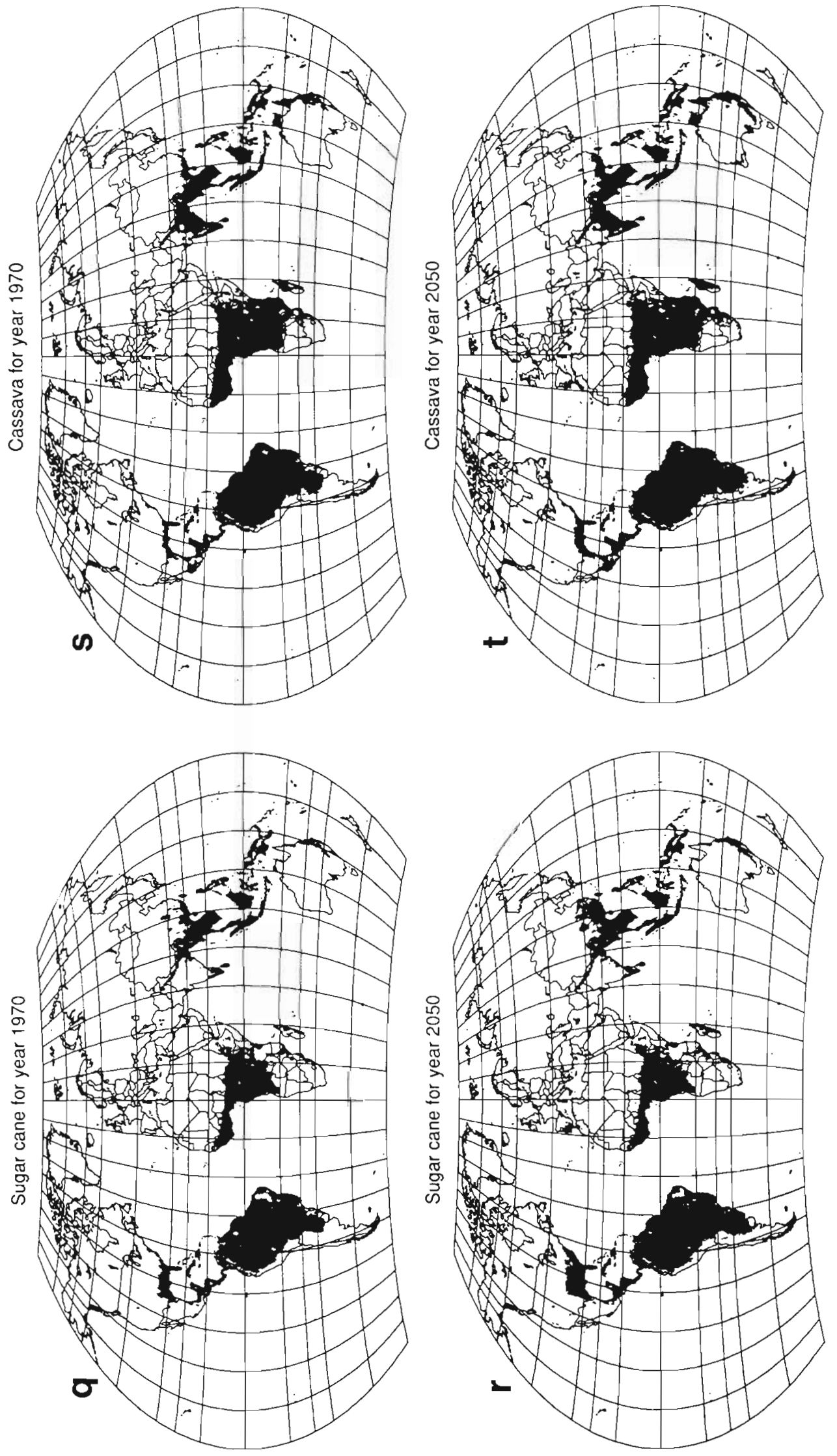

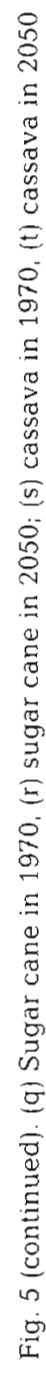


Table 3. Current and future area of the major crops in $10^{3} \mathrm{~km}^{2}$. Reduced area = land lost; stable area $=$ land remaining in agriculture ; expanded area $=$ new land added, after calculating potential area of future agriculture

\begin{tabular}{|c|c|c|c|c|c|}
\hline & $\begin{array}{c}\text { Current } \\
\text { area }\end{array}$ & $\begin{array}{c}\text { Future } \\
\text { area }\end{array}$ & $\begin{array}{c}\text { Reduced } \\
\text { area }\end{array}$ & $\begin{array}{c}\text { Stable } \\
\text { area }\end{array}$ & $\begin{array}{c}\text { Expanded } \\
\text { area }\end{array}$ \\
\hline Temperate maize & 22947 & 29615 & 3222 & 19724 & 9891 \\
\hline Tropical maize & 41064 & 45172 & 350 & 40714 & 4458 \\
\hline Spring wheat & 22348 & 28678 & 3632 & 18716 & 9961 \\
\hline Winter wheat & 20599 & 27199 & 3410 & 17188 & 10010 \\
\hline Rice & 51987 & 57697 & 685 & 51293 & 6386 \\
\hline Millet & 54937 & 65580 & 1122 & 53814 & 11768 \\
\hline Soybeans & 28428 & 33310 & 4815 & 23612 & 9697 \\
\hline Beans & 42031 & 47374 & 5285 & 36745 & 10600 \\
\hline Sugar cane & 29073 & 32690 & 526 & 28547 & 4143 \\
\hline Cassava & 36205 & 39823 & 287 & 35917 & 3905 \\
\hline
\end{tabular}

Most of the current area in which tropical maize is grown continues to support its growth. In contrast, about $15 \%$ of current area (Table 3 ) and of current production (Table 4) of temperate maize is lost. The marginal tropical maize in northern Argentina and Uruguay becomes much more productive (Fig. 5c, d), while the temperate maize disappears from this region (Fig. 5a, b). This shift from one to another type of maize also occurs in other regions, such as in southern Africa and southeast China.

The most obvious change in maize geography is the poleward shift of temperate maize. In Scandinavia where maize is not now grown, large areas become suitable under the changed climatic conditions. A similar change appears in Canada and eastern Siberia (Fig. 5a, b). The only region that becomes much less suitable is the current corn belt of the United States, supporting the projections by Blasing \& Solomon (1984) on retraction of the corn belt in this region. Here production is reduced under future climate conditions and the even moister south- eastern part of this belt becomes unsuitable for maize production.

Wheat (Triticum). Both spring and winter wheat spread polewards (Fig. 5e to h). Productivity increases at high latitudes while the equatorial boundaries become less productive and even unsuitable. The wheat decline at low latitudes is caused in the model by inadequate chilling conditions as winters become too warm. This produces large impacts on wheat productivity in Uruguay and surrounding Argentina, as well as in France, the central United States and southeast Asia. Spring wheat in particular also disappears from these regions (Fig. 5e, f). Although total yield actually increases globally by approximately $30 \%$ (Table 4 ), almost $20 \%$ of current wheat-growing land is lost (Table 3) and spring and winter wheat productivity on current wheat cropland declines 16 to $18 \%$ (Table 4).

Rice (Oryza). Rice distribution increases only slightly (ca $11 \%$; Table 3). This may be due to the sharp temperature and moisture gradient along the northern border of its primary distribution in southeast Asia. A

Table 4. Current and future potential yields of the major crops. The first 2 columns show the area of current cropland which undergoes increases or decreases in yield. Columns $3 \& 4$ provide the proportion of yield lost or gained as measured by unit area or by the worldwide crop population. The last column shows the proportional change in yield by current croplands, i.e. the effect of climate change on the status quo

\begin{tabular}{|lccccr|}
\hline & $\begin{array}{c}10^{3} \mathrm{~km}^{2} \text { with a } \\
\text { decrease in yield }\end{array}$ & $\begin{array}{c}10^{3} \mathrm{~km}^{2} \text { with an } \\
\text { increase in yield }\end{array}$ & $\begin{array}{c}\text { \% change in yield } \\
\text { per unit area }\end{array}$ & $\begin{array}{c}\text { \% change in total } \\
\text { global yield }\end{array}$ & $\begin{array}{c}\text { \% change in yield } \\
\text { of current area }\end{array}$ \\
\hline Temperate maize & 12026 & 19667 & -1.0 & 27.7 & -14.9 \\
Tropical maize & 29372 & 15502 & 2.5 & 12.7 & 1.6 \\
Spring wheat & 14963 & 13824 & -0.2 & 28.1 & -16.4 \\
Winter wheat & 17062 & 12305 & -1.4 & 30.2 & -17.7 \\
Rice & 32824 & 15771 & 1.7 & 13.4 & -1.0 \\
Millet & 29014 & 22605 & 0.1 & 20.7 & -16.8 \\
Soybeans & 19179 & 14870 & 0.4 & 17.4 & -12.9 \\
Beans & 34515 & 14154 & 3.4 & 1.2 & 1.5 \\
Sugar cane & 22637 & 10413 & 4.4 & 14.8 & 3.5 \\
Cassava & 33353 & 5951 & & & \\
\hline
\end{tabular}


great change in climate is required for rice production to cross that gradient. Only in Europe is there a substantial increase in rice area under changed climatic conditions (Fig. 5i, j). Perhaps of greater significance to the dense human populations which depend upon an uninterrupted supply of rice, considerable land now in rice production becomes unsuitable for rice (Table 3) and about twice the area of rice cropland declines in productivity as increases in productivity (Table 4).

The $1.7 \%$ increase in rice yield per unit area generates a $13 \%$ increase in global rice production (Table 4 ). Unlike the precipitous decline in maize and wheat, rice yield on current areas remains stable, showing an insignificant $0.4 \%$ increase. Large potential yield increases appear in South Africa, Europe, Australia and Argentina, but not in the current rice growing regions of southeast Asia (Fig. 5i) where populations depend heavily upon locally grown rice.

Millet (Eleusine, Panicum, Setaria, Echinochloa, Pennisetum, Sorghum). Millet is a very heterogeneous crop. It includes millet (Sahel), kaffir corn (southern Africa), Bajara (India), Ragi (southern India), sorghum (USA and China), Kaoliang (China), and Jowar (India). It requires a dry season to mature. Under a changing climate its range spreads northwards in the northern hemisphere and climatic conditions become unsuitable only in small regions (Fig. 5k, l). The potential area of new millet growth is about 10 times that of millet croplands lost from climate change (Table 3 ). The $1 \%$ increase in unit area yields enhance global millet production by over $20 \%$ (Table 4). Current millet cropland declines in yield slightly $(-1 \%$; Table 4$)$.

Soybeans (Glycine). Soybean is a typical temperate and subtropical crop. Its current distribution covers central South America, southeast Asia and northeast USA (Espenshade \& Morrison 1991). Its potential growth increases considerably in Europe and Canada under changed climate conditions, while the more equatorial borders of its range become less suitable (Fig. 5m, n). Globally it increases over $17 \%$ in area, with potential new area of growth about double that likely to be lost with warming (Table 3). The annual yield changes little per unit area (Table 3) but the increased area of soybean growth (Table 3) generates a $17.4 \%$ increase in potential production at an almost equal cost to productivity on current croplands of $16.8 \%$ (Table 4 ).

Pulses (beans) (Phaseolus). Pulses form a very heterogenous group of crop varieties and the FAO statistics on this group do not distinguish between temperate and subtropical crop varieties. This makes it difficult to define more than generalities in the simulated results. The total geographic extent of these crops increases $13 \%$ (Table 3 ) characterized by a strong poleward shift in the northern hemisphere and a significant decrease in the subtropical/tropical regions (Table 3, Fig. 5o, p). Large parts of India and southeast Africa become less suitable for these crops, mainly due to increasing modelled temperatures. The increase in global productivity of $12.2 \%$ is about balanced by declines on currently farmed areas of $12.9 \%$ (Table 4).

Sugar cane (Saccharum). The potential distribution of sugar cane under changed climate is very similar to the current distribution (Fig. 5q, r). Although the yield decreases somewhat in the tropics, large regions continue to maintain high yields (Table 3) and overall, yields increase per unit area by an impressive $3.4 \%$ (Table 4), and global productivity by $16.2 \%$. Even current sugar cane croplands undergo an increase in production (Table 4). A slight geographic expansion appears in and near Uruguay, as well as in the southeastern United States and southeastern China (Fig. 5q, r). Marginal conditions could occur for introducing sugar cane to Portugal and southwest Spain where today it is absent.

Cassava (Manihot). Cassava is the most geographically stable crop of those simulated. Little change in range can be observed under warmed climate, with the exception of potential expansion into Uruguay and Argentina (Fig. 5s, t). A slight decrease in area in the tropical regions is more or less balanced by slight increases elsewhere (Table 3). Yet, productivity of cassava undergoes important increases; unit area yields jump $4.4 \%$ and currently cropped land produces $3.5 \%$ increases, which generates a global production increase of about $15 \%$.

\section{DISCUSSION}

The success with which the geography of agricultural lands is simulated can be gleaned in part from the verification exercises described above. The modelled distribution of cropped lands on today's earth contains $95 \%$ of the cropped lands observed there, while the remaining $5 \%$ of observed cropped lands is probably to be found under irrigation (non-climatically controlled land uses). The accuracy with which agricultural boundaries emerge and are simulated in this anlaysis suggests a reasonable validity for the method and thus, a considerable advance over more empirical approaches to predicting future land use distribution.

The simulated distributions of individual crop varieties, and their projected yields, also suggest reasonable validity for the approach implemented. The simulated crop distributions all enclose observed distributions (except for that of sugar cane), and the observed patterns of yield distributions illustrated in world atlases appear to be consonant with those simu- 
lated. That simulated yields exceed observed ones is both expectable and a reasonable subject for model improvements.

The current level of model validity provides a sound basis for considering certain emergent phenomena which are implied by application of future climate scenarios to redrawing current crop distributions. Foremost is the difference between agricultural area and agricultural yield under future warmed climate. All of the distributions projected under the GFDL climate scenario increased in land cover between current and doubled $\mathrm{CO}_{2}$ climates (Table 3). Yet, several crop yields on a unit area basis (Table 4) decrease (temperate maize, winter and spring wheat). Even more varieties decline in yield on current croplands, suggesting that warming may be associated with a systematic decline in productivity, or an increase in effort required to produce certain crops.

The crops which decline in unit area productivity or current area yield are those with temperate zone distributions, and with the greatest increases in areal cover after warming $(30 \%$ increase in area total by temperate maize, winter and spring wheat, compared with $13 \%$ by the other crops simulated, from Table 3 ). These productivity-declining varieties also coincide with the distribution of mechanized agriculture, suggesting that available technological responses may be capable of neutralizing the lost unit area production. On the other hand, the temperate crops may be genetically more restricted in the range of acceptable conditions than are varieties with more equatorial distributions, reducing their adaptability to new conditions even more than we have simulated here.

Inspection of crop varieties which increase in yield per unit area (Table 4) is also instructive. The greatest increase is found in cassava $\left(4.4 \%\right.$ greater yield ha ${ }^{-1}$ ), sugar cane $\left(3.4 \%\right.$ greater yield $\left.\mathrm{ha}^{-1}\right)$ and tropical maize $\left(2.5 \%\right.$ greater yield ha $\left.{ }^{-1}\right)$. All of these are grown substantially or entirely for non-human ingestion. Cassava and tropical maize are primarily used as animal foods, while sugar cane in many places provides the basis for alcohol used with fossil fuels to power vehicles and other machinery. Future demands for these products in a technology-dominated, animalconsuming world are likely to increase at least as much as their production is simulated to do, providing some insight into the shift in competitive advantage to be expected in the future demands for both technological and food products from the finite supply of the world's arable land

Another implication of future crop yield projections may be gleaned from the differences between land which is gained and that lost after warming. The burgeoning global population requires a constant and chronically increasing food supply, uninterrupted by the successive crop failures which are required to convince local farmers to switch to less familiar crops. Overall, our projections indicate a relatively major loss of farmed land, even as the area where farming can potentially invade simultaneously undergoes great increases. Indeed, this may be a serious concern in the future because the world's major food crops, rice and spring and winter wheat, which constitute about $40 \%$ of the present global crop productivity (FAO 1983), lose about $8 \%$ (Column 3, Table 3 ) of their currently simulated croplands (Column 1, Table 3). Although they gain about $28 \%$ more land in areas where they are currently absent (Column 5, Table 3 ) the immediate losses of available food production could be considerable. It may be important that after warming, about twice the area of rice-growing land becomes less productive than becomes more productive (Columns 1 \& 2, Table 4).

Contrast this loss and gain projection with the losses and gains projected for the non-food crop varieties discussed immediately above. There, the loss is only about $1 \%$ of current distributions, although the gain is also considerably less than among the food grains, i.e. about $12 \%$ more area can potentially support the nonfood crop varieties after warming than before.

Multiple policy implications emerge from the foregoing projections. Winner and loser countries result from the estimated future crop distribution and yield in e.g. Fig. 5a to t. Given the potential for such important shifts in prosperity and food self sufficiency implied by the models, great care must be taken in pursuing validity in model development and application. Yet, the nature of the models which are used to reach these implications can never be predictive, but only prescriptive. They do not and cannot forecast the future, instead providing estimates of the consequences of specific courses of action, assuming that the forces modeled are the only important ones in a future world, and that no other unsuspected forces will appear. Yet, history teaches us that the forces driving natural and anthropogenic systems in the current world are not likely to be the ones which will dominate the future, that new variables about which we know little or nothing are likely to become prominent, and most important of all, that people have the capability to change future history should they understand its threats well enough. It is in this latter context that the current models are built and will be applied.

\section{CONCLUSIONS}

The concrete results of the analyis emcompass large changes in global agricultural patterns. All regions are affected, but large differences occur. Agriculture in 
high-latitude regions uniformly benefits from the climatic change with projected longer growing periods and increased productivity. Most other regions, however, do not benefit significantly or even lose productivity after such change. In most of these regions differences in moisture availability control the change.

The results must be interpreted cautiously because they are based on simiulation of rain-fed agricultural potentials, and other limiting (soil fertility and structure) or enhancing factors (irrigation) are not taken into account. However, the results give a good indication of potential crop shifts and magnitudes of yield changes on a global rather than regional level.

This analysis further illustrates that with current GIS technology, available global databases and model approaches, it is possible to create comprehensive models which can be used to assess the impacts of a changing climate on crop distribution and productivity. Such models should be linked to integrated land-cover models that simulate the interactions between changing agricultural potentials, land-use demands, and land cover. A general framework of such a model will be published soon (Alcamo et al. in press). The integrated models are needed to understand the interactions between different components of the earth's system and to be able to evaluate the consequences of different policies to mitigate the negative impacts of global change (Anonymous 1990).

Acknowledgements. The foregoing work owes its implementation to the help we received from several persons. Robert Brinkmann of the FAO in Rome provided considerable assistance in obtaining crop data. Gunter Fischer at IIASA, Laxenburg, and Amir H. Kassam, London, spent considerable effort while the authors were resident at IIASA, describing the history and research which resulted in the agro-ecological classification system which we used. Wolfgang Cramer, Colin Prentice and Sandy Harrison provided useful ideas and discussions. We gratefully acknowledge the help of 2 anonymous reviewers. The work was supported by the RIVM, Bilthoven, The Netherlands, and the U.S. EPA, Corvallis, Oregon, through Cooperative Agreement CR 817453-01-0 with Michigan Technological University.

\section{LITERATURE CITED}

Alcamo, J., de Haan, B., De Vries, B., Klein-Goldewijk, K., Kreileman, E., Krol., Leemans, R., Vloedbeld, M., Zuidema, G. (in press). IMAGE 2.0: a comprehensive tool to evaluate policy and scientific issues related to global change. Wat. Air Soil Pollut.

Anonymous (1978). Report on the agro-ecological zones project, Vol. 3, Methodology and results for South and Central America. Food and Agricultural Organization of the United Nations, World Soil Resources Report 48, Rome

Anonymous (1990). The international geosphere-biosphere programme: a study of global change. The initial core projects. No. 12, International Geosphere-Biosphere Programme, Stockholm
Bazzaz, F. A., Fajer, E. D. (1992). Plant life in a $\mathrm{CO}_{2}$-rich world. Scient. Am. 1992: 1821

Blasing, T J., Solomon, A. M. (1984). Response of the North American corn belt to climatic warming. Prog. Biometeorol. 3: 311-321

Bretherton, F. P., Bryan, K., Woods, J. D. (1990). Timedependent greenhouse-gas-induced climate change. In: Houghton, J. T., Jenkins, G. J., Ephraums, J. J. (eds.) Climate change: the IPCC scientific assessment. Cambridge University Press, Cambridge, p. 173-193

Carter, T R., Parry, M. L., Nishioka, S., Harasawa, H. (1992). Preliminary guidelines for assessing impacts of climate change. IPCC report CGER-I005'92. Environmental Change Unit and Center for Global Environmental Research, Oxford

Cramer, W., Prentice, I. C. (1988). Simulation of regional soil moisture deficits on a European scale. Norsk geogr. Tidskr. 42: 149-151

Cramer, W., Leemans, R. (1993). Assessing impacts of climate change on vegetation using climate classification systems. In: Solomon, A. M., Shugart, H. H. Jr (eds.) Vegetation dynamics and global change. Routledge, Chapman and Hall, New York, p. 190-217

Cramer, W. P., Solomon, A. M. (1993), Climatic classification and future global redistribution of agricultural land. Clim. Res. 3: $97-110$

de Wit, C. T, (1965). Photosynthesis of leaf canopies. Agricultural Research Report 663. Centre for Agricultural Publication and Documentation, Wageningen

Espenshade, E. B. Jr, Morrison, J. L. (eds.) (1991). Goode's world atlas. Rand McNally \& Company, Chicago

FAO (1983). FAO production handbook. United Nations Food and Agriculture Organization, Rome

Gates, W. L., Mitchell, J. F. B., Boer, G. J., Cubash, U., Meleshko, V. P. (1992). Climate modelling, climate prediction and model validation. In: Houghton, J. T., Callander, B. A., Varney, S. K. (eds.) Climate change 1992. The Supplementary Report to the IPCC Scientific Assessment. Cambridge University Press, Cambridge, p. 99-134

Higgins, G. M., Kassam, A. H., van Velthuizen, H. T., Purnell, M. F. (1987). Methods used by FAO to estimate environmental resources, potential outputs of crops, and population-supporting capacities in developing nations. In: Bunting, A. H. (ed.) Agricultural environments: characterization, classification and mapping. C.A.B. International, Wallingford, p. 171-183

Houghton, J. T., Callander, B. A., Varney, S. K. (eds.) (1992). Climate change 1992. The supplementary report to the IPCC scientific assessment. Cambridge University Press, Cambridge

Leemans, R. (1992). Modelling ecological and agricultural impacts of global change on a global scale. J. scient. ind. Res. 51: 709-724

Leemans, R., Cramer, W. (1991). The IIASA database for mean monthly values of temperature, precipitation and cloudiness on a global terrestrial grid. Research Report RR-91-18. International Institute of Applied Systems Analyses, Laxenburg

Manabe, S., Wetherald, R. T. (1987). Large-scale changes in soil wetness induced by an increase in carbon dioxide. J. atmos. Sci. 44: 1211-1235

Matthews, E. (1983). Glojal vegetation and land use: new high-resolution data bases for climate studies. J. Clim. appl. Meteorol. 22: 474-487

Matthews, E. (1985). Atlas of archived vegetation, land-use and seasonal albedo data sets. Technical Memorandum 86199. NASA, New York 
Mitchell, J. F. B., Manabe, S., Meleshko, V., Tokioka, T (1990). Equilibrium climate change and its implications for the future. In: Houghton, J. T., Jenkins, G. J., Ephraums, J. J. (eds.) Climate change: the IPCC scientific assessment. Cambridge University Press, Cambridge, p. $131-172$

Monserud, R.A., Leemans, R. (1992). The comparison of global vegetation maps. Ecol. Model. 62: 275-293

Olson, J., Watts, J. A., Allison, L. J. (1985). Major world ecosystem complexes ranked by carbon in live vegetation: a database. NDP-017 Oak Ridge National Laboratory, Oak Ridge

Parry, M. (1992). The potential effect of climate changes on agriculture and land use. Adv. ecol. Res. 22: 63-92

Parry, M. L., Carter, T. R., Konijn, N. T. (1988). The impact of climatic variations on agriculture, Vol. 1, Assessments in cool temperate and cold regions. Kluwer Academic Publishers, Dordrecht

Penman, H. L. (1948). Natural evapotranspiration from open water, bare soils and grass. Proc. R. Soc. (Ser. A) 193: $120-145$

Prentice, I. C. (1992). Climate change and Iong-term vegetation dynamics. In: Glenn-Lewin, D. C., Peet, R. K., Veblen, $\mathrm{T} T$. (eds.) Plant succession: theory and prediction. Chapman \& Hall, London, p. 293-339

Prentice, I. C., Cramer, W., Harrison, S. P., Leemans, R., Monserud, R. A., Solomon, A. M. (1992). A global biome model based on plant physiology and dominance, soil properties and climate. J. Biogeogr. 19: 117-134

Prentice, I. C., Sykes, M. T., Cramer, W. (1993). A simulation model for the transient effects of climate change on forest landscapes. Ecol. Model. 65: 51-70

Rind, D., Rosenzweig, C., Goldberg, R. (1992). Modelling the hydrological cycle in assessments of climate change. Nature 358: 119-122

Rosenberg, N. J., Crosson, P. R. (1991). Processes for identify- ing regional influences of and responses to increasing atmospheric $\mathrm{CO}_{2}$ and climate change - the MINK project. An overview. TR052A. U.S. Department of Energy, Washington, DC

Rosenzweig, C. (1985). Potential $\mathrm{CO}_{2}$-induced climatic effects on North American wheat-producing regions. Clim. Change 7: 367-389

Rosenzweig, C. (1993). Modeling crop responses to environmental change. In: Solomon, A. M., Shugart, H. H. (eds.) Vegetation dynamics and global change. Chapman \& Hall, New York, p. 306-321

Saxton, K. E., Porter, M. A., McMahon, T. A. (1992). Climatic impacts on dryland winter-wheat yields by daily soil water and crop stress simulations. Agric. For. Meteorol. 58: $177-192$

Shugart, H. H., Leemans, R. Bonan, G. B. (eds.) (1992). A systems analysis of the global boreal forest. Cambridge University Press, Cambridge

Smith, T. M., Leemans, R., Shugart, H. H. (1992). Sensitivity of terrestrial carbon storage to $\mathrm{CO}_{2}$ induced climate change: comparison of four scenarios based on general circulation models. Clim. Change 21: 367-384

Solomon, A. M. (1986). Transient response of forests to $\mathrm{CO}_{2}$ induced climate change: simulation experiments in eastem North America. Oecologia 68: 567-79

Solomon, A. M. (1992). The nature and distribution of past, present and future boreal forests: lessons for a research and modeling agenda. In: Shugart, H. H., Leemans, R., Bonan, G. B. (eds.) A systems analysis of the global boreal forest. Cambridge University Press, Cambridge, $p$ 291-307

Swift, L.W. Jr (1976). Algorithm for solar radiation on mountain slopes. Water Resour. Res. 12: 108-112

Thornthwaite, C. W. Mather, J. R. (1957). Instructions and tables for computing potential evapotranspiration and the water balance. Publ. Climatol. 10: 185-310 